\title{
Social Work and the Changing Face of the Digital Divide
}

\author{
Jan Steyaert and Nick Gould
}

\begin{abstract}
Jan Steyaert is professor in the Netherlands (Fontys) and UK (University of Southampton). Research interests are technology and quality of life (digital divide, internet and loneliness, assistive technology, accessibility), information management in social services (client index systems) and active citizenship. He has published widely on the application of technology in human services as well as on the dynamics between technology and social quality of society. Nick Gould is professor of social work at the University of Bath, UK. He has researched and published widely in the fields of professional learning, social informatics, mental health and evidence-based practice.
\end{abstract}

Correspondence to Professor Jan Steyaert, Fontys University of Applied Sciences, Department of Social Studies, PO Box 347, 5600 AH Eindhoven, The Netherlands. E-mail: j.steyaert@fontys.nl

\section{Summary}

In this article, the concept of digital divide and its relation to social exclusion is analysed. After describing the several facets of the digital divide, the question is asked whether the divide is widening or narrowing? The definition of digital divide is reconsidered and the article argues that access to the technology alone is but a very rudimentary indicator of actually making use of digital opportunities. This is expanded in the section on risks arising from digital exclusion. Finally, implications of this approach of the digital divide for social work and social care are considered.

Keywords: digital divide, social exclusion, information society

\section{Introduction}

During the last decade, it has become recognized in social work and social policy that information exchange and management are fundamental to the effective and equitable delivery of services. It is more than a desirable means of making administration more efficient; technology often structures the interface between those who use services and those who provide them. Deficiencies in the exchange of information are likely to obstruct access to services. 
Social work commentators have often shown themselves reluctant to accept that information, and the technology that supports the management of information, play a defining role. Their critiques can be categorized under two headings: the humanist and the anti-humanist approaches. The humanist case is an objection to technology as representing an intrusion into the person-centred project of social work, displacing the authenticity of the encounter between worker and service user and replacing it with preoccupations with accountability and bureaucratic efficiency (Burton and van den Broek, 2008). A corollary of this is the argument that human reasoning and the heuristics of human problem solving cannot be reduced to algorithms and depend on tacit knowledge (Sapey, 1997, and see also Leung's contribution to this Special Issue). The latter position overlaps with the anti-humanist case, so called because it derives from the poststructuralist and related Foucaultian analyses of social work (Webb and McBeath, 1989). It focuses on the role of technology in regulating the subjectivity of the person, extending the capillaries of power between actors. This line of critique returned recently in the social work literature in Parton's (2008) assertion that social work is being transformed from the 'social' to the 'informational'. His argument is that there has been 'a shift from a narrative to a database way of thinking and operating' (Parton, 2008 , p. 253) within which the close relationship with individuals is replaced by a more distant concern with subjects reconstituted as the aggregation of the data held about them.

Much of this literature is characterized by an implicit pessimism about the potentiality of technology, and an implicit contention that a form of practice could exist that stands outside the sordid business of using technology to collate and disseminate information. It is difficult to locate this alternative reality given social work's historical background as a bureauprofession. As the authors have commented elsewhere, social work arguably lies within a historical tradition that goes back to sixteenth-century poor law administration. Indeed, Parton acknowledges that the 'informational' character of social work is not new, but has become more dominant with the arrival of information and communication technologies. The recent modernization of social services is made possible and shaped by information technologies. The proliferation of activities such as care management, commissioning, contracting and regulation required by these innovations necessitate the assembly and manipulation of large amounts of data (Steyaert and Gould, 1999).

Nevertheless, this is emphatically not to argue that the operation of technology is neutral in its impacts on users of services, even though there is probably no going back in terms of the deployment of information technology. An emergent risk is that differential access to familiarity with technology can reinforce social inequalities and add to the vulnerabilities of individuals and social groups that are most in need of social work intervention. Connected citizens are getting better services, within both the private 
and the public sector. For example, UK citizens who buy their train tickets online are said to save on average a third of the costs (see $w w w$.thetrainline. com) and citizens who have internet accounts receive a higher interest rate from their banks. Similar examples can be found in public services, including social work (e.g. by finding online information about topics like debt, addiction, divorce, etc. or by getting quicker online support such as counselling (see also Murphy et al. in this Special Issue)).

This is where the concept of the 'digital divide' becomes pivotal: the risk of less access to services as well as less choice and possibly greater costs may result in social exclusion because the person does not have access to new technology or skills to use that technology. This is also where social work becomes involved, as one of the professions fighting social exclusion. So far, the implications of the digital divide have received very little attention within the social work literature, although Parrott and Madoc-Jones (2008) have latterly drawn attention to the possibility of new technology assisting social workers to address social exclusion. It is within this perspective of social workers' broader role within the social exclusion agenda in combination with technology that we focus on the digital divide.

It is now fifteen years since the concept of the 'digital divide' was added to our vocabulary. A search into its origins on Benton's digital divide discussion list (see www.digitaldivide.net) found traces going back to 1995, when journalists of the LA Times started using it, as did Al Gore in May 1996. The first scholarly use of the concept can be traced back to a 1997 publication (Katz and Aspden, 1997), as, interestingly, the first 'Falling through the Net' survey in 1995 did not use the term (US Department of Commerce, 1995). Since these first occurrences in newspapers, policy and science, the concept of the digital divide has proliferated. Rereading these first publications raises the question of whether we are still talking about the same thing or whether new definitions and concepts are called for. In 1995, a mere 8 per cent of the population had access to the internet (regardless of home or work use) and getting a connection basically involved a dial-up connection, implying slow and mostly metered access. At the end of 2008, recent surveys indicate that in some countries, up to 90 per cent of households have access at home. In the developed countries, slow dial-up connections have rapidly been replaced by faster non-metered access through cable or DSL, and in-house connections have become wireless (see www.internetworldstats.com for an overview of recent surveys).

In this paper, the concept of the digital divide will be considered. After describing several facets of the digital divide, a conclusion will be reached as to whether the divide is widening or narrowing. The definition of the digital divide will then be reconsidered and it will be argued that access alone is but a very rudimentary indicator of actually making use of digital opportunities. This argument will be expanded in the section on risks arising from digital exclusion and, finally, implications for social work and social care will be considered. 


\section{The many facets of the digital divide}

The digital divide surfaces at a global, geo-political regional and household level, at each of which different dynamics play and specific solutions need to be identified.

On a global level, we need to acknowledge that, despite the euphoria about the internet, only 1.5 billion people have access; this is approximately 22 per cent of the world's population of 6.6 billion (www.internetworldstats. com, December 2008). Industrialized countries, with only 15 per cent of the world's population, are home to 88 per cent of all internet users. The range differs from 445 persons per 1,000 having home internet access in the OECD countries to only 12 per 1,000 in the least developed countries (UNDP, 2007).

Despite rapid diffusion in the developing countries, London is said to still have more internet domains than the whole of Africa. Around the turn of the century, Finland alone had more internet users than the whole of Latin America (Forum, 2002). These are not new discrepancies: in relation to 'old' technology, the telephone directory for Manhattan is bigger than that of the African continent, and 50 per cent of the world's population has never made or received a telephone call.

While the analysis of the digital divide on a global scale normally entails comparing large regions (e.g. Africa or North America), it is clear that the use of such units hides disparities within these geo-political regions. In the European Union, the number of households having a connection to the internet was 60 per cent in 2008 (Eurostat data for EU-27). A closer look per country unveils discrepancies ranging from as low as 25 per cent (Bulgaria) and 30 per cent (Romania) to as high as 84 per cent (Sweden) and 86 per cent (the Netherlands). And within countries, there is geographical variety between strong and weak economic regions as well as between cities and rural areas. Interestingly, recent discussion has highlighted that the lack of broadband access in rural areas is not so much a result of consumer choice as one of internet service providers' strategy. Their first commitment is to a sound business plan and happy investors. This results in 'cherry picking' - a situation in which private companies concentrate their investments in those parts of the country that promise to yield rich returns-on-investments (Graham and Marvin, 1994). Some locations are, due to socio-demographic characteristics of their population, 'sticky places', where private investments tend to flourish; others are 'slippery places', which private investors tend to avoid (Markusen, 1999).

Finally, even country by country or region by region analyses hide differences of internet availability in households. There are at least seven significant socio-demographic fault lines along which the availability varies. These include income, educational level, gender, age, employment status, ethnicity and type of household (e.g. single-parent). Access to the internet 
varies, as can be expected: the higher the household income, or the younger, or the more educated, or the more Western ethnicity, the more they have the internet. We could be surprised that there is so little surprise that precisely these variables influence internet access. It has been used as a strong argument to state that the digital divide is not that digital, but another facade of social exclusion (De Haan and Rijken, 2002). As such, inequalities of access to new technology are little different from those relating to health care, to education or to employment.

In the remainder of this article, we will focus on the differences between households in Western societies. This special issue of the British Journal of Social Work features another article describing the digital divide from a non-Western perspective (Chi Yee and Fung, 2009).

\section{Is the divide widening or narrowing?}

Connectivity to the internet is a highly fluid entity. On a global scale, the position any specific country takes on the map of internet access continuously changes over time. Countries jump positions with other countries and improve or worsen their chances in the race of connecting citizens to the internet. Least developed countries like Togo or Benin are leaping ahead with mobile phone usage because, in the early stages of diffusion, the infrastructure does not rely on heavy investment. Some countries make the link between being connected and generating income, establishing imitations of Silicon Valley, such as the often quoted Indian Bangalore technology valley in India: they transmogrified 'from bullock carts to cyber marts' (Singhal and Rogers, 2001).

The divide along socio-demographic fault lines is equally in a permanent flux. Gender is one of the seven indicated fault lines and used to relate strongly to the digital divide. However, things have greatly improved and gender is no longer a strong indicator for access to technology. Men and women alike have similar levels of access to new technology such as mobile phones and internet connections. Nevertheless, there remains a relationship between gender and the amount of time spent on the internet.

Gender is not the only fault line where the digital divide is closing. However, while some divides narrow, others increase. In the recent past, there has been a considerable shift away from income and education levels as prime factors in the digital divide towards age. The digital divide is now primarily age-related. For instance, a survey of patterns of internet use in Britain found there is still a massive gap between age groups: only 31 per cent of retired people use the internet, compared with 81 per cent of those in work and 97 per cent of students - a pattern that has persisted since 2003 (Dutton and Helsper, 2007).

Interestingly, the reasons as to why one does not have a computer or internet access also change according to age. While young age groups cite high 
costs and opportunities elsewhere (school or work) as a significant reason not to have home internet access, the older age groups refer to lack of interest and lack of digital skills. This raises the issue of drawing the line between diversity and a real divide. If senior citizens are comfortable in using the old technology and see no interest in acquiring new technology, should we still define this as a digital divide or as an informed choice? Are older people socially excluded because they have no interest in the latest gadgets? Do they become socially isolated because they rely on telephone calls rather than e-mail (as grandparents usually do to communicate with their grandchildren)? Are they economically disadvantaged because they buy books in the bookshop rather than at www.amazon.com?

To a large extent, the answer to these questions depends on the speed at which old technology remains a valid option, namely as long as books, travel, etc. can be bought in the traditional way, at no additional cost, and as long as friends can still be called on the telephone. Gradually, as the customer base of e-services increases, we do see services that rely on old technology becoming less competitive; for example, e-accounts at banks get a slightly higher interest rate. Travel and holidays booked through the internet offer better prices and more choice. An increasing amount of public service provision relies heavily on internet use (e.g. driving licence renewal, quotes for state pensions). Utility providers such as gas and electricity companies favour customers using online bills rather than printed and posted bills. As and when these developments increase and e-products or e-services offer better value, non-connected citizens will indeed be disadvantaged and the diversity in internet access will become a divide, contributing to social exclusion.

\section{The XXL edition}

The debate about whether the digital divide is widening or narrowing needs to be expanded and made more complex. Up to now, most attention has focused on the varied ways people access the internet. That is, however, only the XS version of the digital divide debate. As scholarly work in this area expands, we are outgrowing this size and need to gradually move to an XXL version of the analysis. Such a shift involves adding several layers of complexity to the current debate.

A first relatively small complexity that needs to be added is to broaden the definition of access. While surveys used to suffice with the question 'Do you have access to the internet at home?' as an indicator, the current variety of connections calls for differentiation. One should be able to distinguish between dial-in connections, ISDN, cable, DSL, fibre to the home, wireless, etc. Though this is of interest to service providers, the exact type of technology is actually not very critical to the digital divide debate. The more significant underlying issues are the availability of 
metered versus unmetered access (as unmetered access generates substantially richer usage patterns) and the bandwidth of the connection.

A second complexity involves internet usage rather than access. Although citizens are notoriously unreliable when asked about the ways they spend their time, and time diary surveys are complex as well as expensive, it is safe to state that, on average, time spent using the internet has increased significantly over the last three years. Such developments have gone hand in hand with the shift from metered to unmetered access. It also generates a debate on time displacement, whether internet time is taken from television time or 'social time' (see, e.g. the special fall 2002 issue of $I T \&$ Society). Applications such as peer-to-peer file sharing also call for a distinction between internet time as foreground or background activity, similar to radio or television.

Again, main overall trends of increased internet time disguise variations across socio-demographic groups. Surveys indicate that within the group of citizens with access to the internet, regularity of usage varies greatly, predominantly by age. The differences in access are consequently aggravated by the differences in usage patterns: older citizens have less access and, even when they have access, they make less use of the technology. Differences in the level of access and usage will not always strengthen each other. In terms of income, there seems to be little variation in frequency of using e-mail once one has access (that is with the exception of the lowest-income category, showing very frequent usage, most likely as a result of the high percentage of students in this category). Limiting an analysis of the digital divide to having access to the technology is consequently only scratching the surface of the issue.

Another complexity to be added to the digital divide debate is deconstructing the concept of internet use. There is so much one can do on the internet that the simple observation that somebody has access to and is spending a certain amount of time on the internet is almost meaningless. Does one send e-mails to friends, chat with strangers, play a game, download music, hunt for scholarly information or a new job, watch movies on YouTube, read e-newspapers or search health information for a neighbour? It is a fair assumption that these usages differ in terms of their expected contribution to somebody's social position in society as well as to overall social quality. Some applications provide users with increased resources; others can be fun but contribute little.

Consequently, we need to start untangling some of these different activities and focus on 'content preferences'. Research into television has already deconstructed the concept of television into viewing attitudes and has shown that preference for certain types of programmes goes hand in hand with, for instance, political attitudes and social participation (HoltzBacha and Norris, 2001). From a social perspective, having a television and watching become less relevant indicators than what kind of content is being watched. 
There are indications that the increased use of the internet (in terms of time online, and in terms of bandwidth used) can be attributed to increased use for entertainment. This is similar to earlier innovations. In the sixties, television was heralded as a great platform for public education - an assumption that is now more contentious. Neil Postman criticized this development, claiming we are 'amusing ourselves to death' (Postman, 1985). A similar development can be seen with the internet. While it was welcomed as a tool for the "homo rationales', it is rapidly being taken over by the 'homo ludens'.

Although we are not comfortable with and want to avoid stereotyping, the evidence seems to indicate that the digital divide is developing into a divide on who uses the internet for what. Research on internet use among Swiss households found that entertainment use of the internet varies across socio-demographic groups: '.. people with higher education use the Internet for informational and service-oriented purposes; people with lower education use the Internet significantly more for entertainment reasons' (Bonfadelli, 2002). This also relates to low-income households being surprisingly well represented among broadband users as a consequence of file-sharing applications, exchanging music and movies.

Another indication that content preferences are more relevant than access comes from research into the effects of home internet usage on school results. Those who used the internet at home had better school results, although the effects differed across subject areas. But, surprisingly, the overall effect was bigger for girls than boys. The reason why could be found in that boys used their technology for games and fun significantly more than the girls did: 'There was a statistically significant positive association between pupils' use of ICT out of school for leisure purposes and decreases in attainment. This effect was over twice as large an effect as the positive association of using ICT for educational purposes. In other words, it is not access or general use of ICT per se that could raise attainment, but rather how the technology is used that matters' (Valentine et al., 2005, p. 8).

Given these differences in content preferences and the impact of types of information behaviour on school results and other socially desirable results, it becomes clear that the digital divide changes into an information divide. The medium is no longer the most critical element; information behaviour becomes the main driver of the influence of technology on social exclusion. This raises ethical issues (is the digital divide consequently a private, individual responsibility and no longer relevant to social work?) as well as professional issues (which are the appropriate social interventions to use?).

\section{Content preferences, responsibility and public intervention}

Once we expand our analysis of the digital divide to include content preferences, a whole new set of questions emerges, related to the balance between 
public, private and individual responsibility for closing the digital divide. Is the divide mainly a result of personal information preferences, with responsibility falling on households to determine their own priorities, with internet access simply one of many competing priorities for their finite disposable income?

The issue over who is responsible for the risks (and the outcomes of risk taking) has interesting parallels with recent social policy debates over public and private choice. Mainstream neoclassical economics would regard new technology as essentially private goods. For those who adhere to a so-called 'public choice theory' perspective, the interference of the state to influence the distribution of private goods only serves the self-interest of bureaucrats seeking to extend their influence and budgets, while at the same time creating inefficiencies in the market. However, critiques of public choice theory emphasize the effects of actual information asymmetries that mean that the market will never meet the demand for many forms of service; instead, it will 'cherry pick' the most profitable and least risky parts of the market (Barr, 1992; Rothstein, 2002). However, if we see internet access as a public good, then other kinds of argument kick in to justify interventions providing internet access for the whole society. The justification for seeing the internet as a public good rests both on the narrow economic definition that 'it is not possible to exclude others from using the good' but also the recognition that lack of access is, as we have seen, a cumulative risk of undermining the social inclusion and social cohesion that benefits everyone. These seemingly rarefied arguments about markets and rationality have significant implications for thinking about how to ameliorate the impact of digital divides on the provision of social services.

\section{Social work's interventions}

However, analysing and describing the problem of the digital divide are one thing; finding solutions to it and developing 'remedies' another. Social work has been one of the actors developing and implementing such remedies. Over the past decade, several social interventions have been trialled, evaluated and implemented. But as the nature of the digital divide has changed, so the nature of these interventions changed.

When the digital divide was first identified as a new challenge in social policy, initiatives emerged to provide public access for those not having access at work or at home. Public libraries were among the first to offer such opportunities, but were not the only organizational framework for public access points. Other frameworks were local schools, community technology centres (CTCs) and the commercial sector (cybercafés). While the commercial public access points tend to cluster in rich and tourist areas, others focus on low-income neighbourhoods, the first of which was probably the Playing to Win project in Manhattan, as early as 1983. 
The majority of these initiatives did not limit their intervention to providing access to computers and internet connections, but expanded their services to include computer training and awareness raising. CTCs, in particular, became hubs for acquiring the information skills so necessary in the information age. The shift from providing access to digital skills was not the end of developments. As these basic building blocks for social 'e-inclusion' became established, the aims and activities moved towards applying information tools and skills for enhancing labour market participation and building social capital in low-income neighbourhoods. Technology became a tool for community development, in both an economic and a social sense. Using the internet is no longer an end in itself, but equally a tool for working on social inclusion.

Not all social interventions tackling the digital divide are geared towards public access. Another strategy recognizes the differences between gaining access at a public place versus access in the household. The aim consequently became to provide low-income households with computers for home use, sometimes geared specifically towards households with schoolaged children, so as to enable both parents and children to benefit from technology. Some initiatives rely on fiscal regimes to make the purchase of a computer more attractive. As market prices for technologies drop (and most likely also because of the changed economic situation), these tax programmes have been cut in some countries.

Another approach to providing home access for low-income households involves recycled or refurbished computers, involving vocational training of less-educated staff to improve their labour market position. Interestingly, the biggest Dutch initiative in this area stopped its work in late 2003 as mainstream computers became cheaper and the economic recession limited the availability of second-hand computers. Also, users of refurbished computers were not always able to make use of the latest software. These same issues are also relevant to the discussion about shipping old computers from Western companies to developing countries.

In addition to initiatives geared towards public access or getting computers into households, some strategies focused on changing technology and its diffusion patterns. For instance, some argue that the monopoly of Microsoft is a threat to a cohesive information society, as their software is too expensive. They consequently argue that open-source software is a good alternative to lower the 'cost of operation' of new technology and increased usage of such open-source software can contribute to bridging the digital divide. However, working with open-source software currently relies on users having strong digital skills and confidence, which are two elements citizens on the wrong side of the digital divide seldom have.

Another strategy focuses specifically on the position of disabled citizens in the digital divide and the lack of accessibility of technology (Steyaert, 2005). 
In many Western countries, this led to the emergence of policy action and a legal framework that called on technology providers (hardware, software and content) to construct their products and services so as to maximize accessibility. The 1998 update of the US Rehabilitation Act (see www. section508.gov) indicates that government agencies in their procurement of products and services need to take into account accessibility. This and similar laws have resulted in companies like Microsoft and Adobe making a real investment in improving the accessibility of their software. ${ }^{1}$

Third, some spatial differential access patterns are not so much related to choices of consumers as those of companies. As indicated earlier, when it comes to deployment of new infrastructure, there is a tendency for companies to 'cherry pick'. Again, in some countries, there has been some policy action and a legal framework to enforce universal access.

Within this landscape of social interventions tackling the divide, the observation can be made that the digital divide has not only changed as a result of social interventions, but equally as a result of changing technology. Software has become more reliable and user-friendly; hardware has become cheaper and easier to handle to the point of being sold at low-cost supermarkets. Subscribing to an internet service provider is nowadays a smooth process compared to the struggle it took to get an internet connection a decade ago. The infrastructure of the information society has matured considerably.

Part of this changing technology is the development from work tools (word processing, number crunching, databases) to multi-purpose tools. Laptops are now marketed as 'entertainment centres'. Leisure applications such as watching films, downloading music or playing games are probably more common usages of new media than 'serious' applications. Within this context, social work faces the challenge to develop new social interventions, new 'remedies' to tackle the 'content preferences' version of the divide. If it is no longer variations in access to technology or digital skills that are the basis for social exclusion, but the type of applications people use the technology for, providing low-cost computers and the IT skills to use them are no longer appropriate as the sole strategies.

Other remedies are needed. From a technological perspective, it would be possible to use internet filtering and, for example, limit publicly subsidized computer and internet access to 'good content' and exclude gaming and entertainment content. From a social work perspective, however, such an approach would raise discussions about censorship and paternalism. Outside social work, the use of 'persuasive technology' (technology that guides and changes the behaviour of citizens in ways that are good for them and society) is less disputed. We are all familiar with applications of persuasive technology, such as the car that beeps intrusively if the driver does not wear a seatbelt.

Health care has been faced with a similar challenge of finding new interventions, when it became clear human behaviour had become an important 
factor in endangering health. Smoking, drinking alcohol and lack of physical activity became as problematic for health as germs and accidents. Traditional health care (GPs, hospitals, pharmacies, etc.) consequently has been expanded, with public health initiatives geared towards behavioural changes that promote healthy lifestyles. Citizens are now subject to a whole range of initiatives that dissuade them from smoking or excessive drinking, from becoming overweight. Such approaches raise issues both relating to 'what works' in terms of changing behaviour, as well as 'what is allowed', in terms of where personal freedom allows people to act foolishly (Leichter, 1991).

Tackling the digital divide will need a similar approach to that of 'public social work' so that not only internet access is promoted and digital skills are enhanced, but also that people are encouraged to use the internet in ways that positively contribute to their social quality of life.

\section{Conclusion: implications for social work}

Over the last decade, we have seen a growing interest in fighting the digital divide and preventing technology from becoming a new platform for social exclusion. In an unusual coalition, this movement united governments at all levels, profit as well as non-profit organizations and community development workers. There was a great sense of urgency, resulting in a myriad of social interventions. Lately, in many countries, the interest has weakened considerably. One could be sceptical and suggest that government/business were only interested in the digital divide issue up to the point at which a sufficient critical mass of e-consumers was established.

While interest decreases, complexity increases. It is now clear that solving the digital divide is more complex than 'providing the kit' and several layers of complexity need to be added to our understanding of the digital divide. Additionally, digital exclusion cannot be separated from more general social exclusion patterns, as both reinforce each other, as this paper has argued. As we begin to see the growth of social work services online (Waldman and Rafferty, 2006), these issues will become increasingly in the forefront of social work's everyday practice.

While social interventions aimed at reducing the digital divide have expanded from their original focus of providing access to include enhancing digital skills and inviting citizens to become information producers (the so-called Web 2.0), they have yet to address the challenge posed by the expanding entertainment nature of the internet and the differences in content preferences across socio-economic groups. As part of its overall concern with reducing social exclusion, social work needs to ensure that the wide availability of the information opportunities of the internet does not only benefit the already information-rich. If not, the work of Neil Postman becomes relevant again, but this time with a social exclusion 
element added to it: will socially vulnerable citizens be amusing themselves to death?

Accepted: February 2009

1. www.microsoft.com/enable/ and www.adobe.com/accessibility/.

\section{References}

Barr, N. (1992) 'Economic theory and the welfare state: A survey and interpretation', Journal of Economic Literature, 30, pp. 741-803.

Bonfadelli, H. (2002) 'The internet and knowledge gaps: A theoretical and empirical investigation', European Journal of Communication, 7(1), pp. 65-84.

Burton, J. and van den Broek, D. (2008) 'Accountable and countable: Information management systems and the bureaucratization of social work', British Journal of Social Work, 38(3), pp. 493-506.

Chi Yee, J. and Fung, J. (2009) 'Tackling the digital divide', British Journal of Social Work, in press.

De Haan, J. and Rijken, S. (2002) 'The digital divide in the Netherlands: The influence of material, cognitive and social resources on the possession and use of ICTs', Electronic Journal of Communication, 12(1\&2).

Dutton, W. H. and Helsper, E. (2007) Oxford Internet Survey 2007 Report: The Internet in Britain, Oxford, Oxford Internet Institute.

Forum, W. E. (2002) Annual Report of the Global Digital Divide Initiative, Geneva, WEF.

Graham, S. and Marvin, S. (1994) 'Cherry picking and social dumping: British utilities in the 1990s', Utilities policy, 4(2), pp. 113-19.

Holtz-Bacha, C. and Norris, P. (2001) "“To entertain, inform and educate": Still the role of public television in the 1990s?', Political Communication, 18(2), pp. 123-40.

Katz, J. and Aspden, P. (1997) 'Motivations for and barriers to internet usage: Results of a national public opinion survey', Internet Research: Electronic Networking Applications and Policy, 7(3), pp. 170-88.

Leichter, H. (1991) Free to Be Foolish: Politics and Health Promotion in the United States and Great Britain, Princeton, Princeton University Press.

Markusen, A. (1999) 'Sticky places in slippery place: A typology of industrial districts', in Barnes, T. and Gertler, M. (eds), The New Industrial Geography, London, Routledge.

Parrott, L. and Madoc-Jones, I. (2008) 'Reclaiming information and communication technologies for empowering social work practice', Journal of Social Work, 8(2), pp. 181-97.

Parton, N. (2008) 'Changes in the form of knowledge in social work: From the "social" to the "informational”?', British Journal of Social Work, 38, pp. 253-69.

Postman, N. (1985) Amusing Ourselves to Death: Public Discourse in the Age of Show Business, New York, Viking.

Rothstein, B. (2002) 'The universal welfare state as a social dilemma', in Rothstein, B. and Steinmo, S. (eds), Restructuring the Welfare State: Political Institutions and Policy Change, Basingstoke, Palgrave Macmillan. 
Sapey, B. (1997) 'Social work tomorrow: Towards a critical understanding of technology in social work', The British Journal of Social Work, 27(6), pp. 803-14.

Singhal, A. and Rogers, E. M. (2001) India's Communication Revolution: From Bullock Carts to Cyber Marts, New Delhi, Thousand Oaks, CA, Sage Publications.

Steyaert, J. (2005) 'Web based higher education, the inclusion/exclusion paradox', Journal of Technology in Human Services, 23(1/2), pp. 67-78.

Steyaert, J. and Gould, N. (1999) 'Social services, social work and information management, some European perspectives', European Journal of Social Work, 2(2), pp. $165-75$.

UNDP (2007) Human Development Report 2007/2008, New York, UNDP.

US Department of Commerce (1995) Falling through the Net: A Survey of the "Have Nots" in Rural and Urban America, US Department of Commerce, available online at www.ntia.doc.gov/.

Valentine, G., Marsh, J. and Pattie, C. (2005) Children and Young People's Home Use of ICT for Educational Purposes, London, DfeS.

Waldman, J. and Rafferty, J. (2006) 'Experience from virtual social work practice: Implications for education', Journal of Evidence Based Social Work, 3(3/4), pp. 127-48.

Webb, S. and McBeath, G. (1989) 'A political critique of Kantian ethics in social work', British Journal of Social Work, 19, pp. 491-506. 